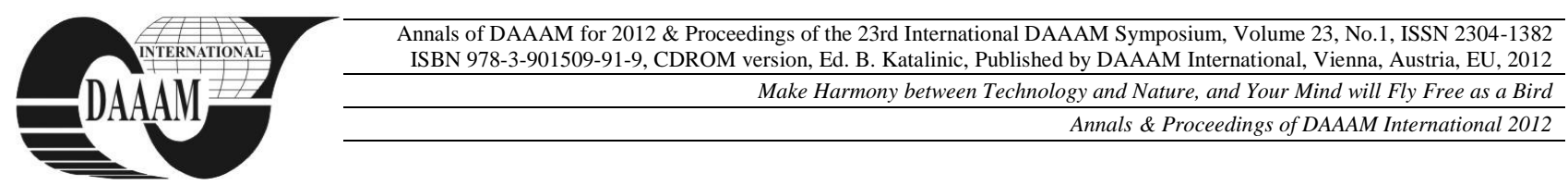

\title{
MATHEMATICAL MODEL OF ROOM OCCUPANCY
}

\author{
PERUTKA, K[arel]
}

\begin{abstract}
The paper deals with the original mathematical model couting room occupancy. This model was created in order to count the room occupancy before the timetable is created. The model works with scheduled groups of students and study plans. Since the number of lecture halls, seminary rooms and laboratories is given, the model also gives the occupancy of each type of room. The model usage is now limited only for use at the the author's faculty. After introduction part, the new and original model of room occupancy is presented, equations first, and list of used symbols after. Finally, the sample model usage is provided.
\end{abstract}

Keywords: Mathematical modeling, MS Excel, faculty timetable

\section{INTRODUCTION}

The education is the mile stone of the mankind rise. Timetable is one of the most important documents during the studies from the students' point of view. Nice paper about important role of engineers in the society was published by Katalinic (Katalinic, 2010). According to this paper, the continuously increasing knowledge of the civilization is connected with technology and it has important role in the globalization of our world.

There are several papers dealing with timetable construction, such as the implementation of university course and examination system which works with original model (Dimopolou \& Miliotis, 2001) and it was automated as a computer network based system using centralized database (Dimopolou \& Miliotis, 2004), or constructing timetable using integer programming (Daskalaki \& Birbas, 2005). Decision support system for university timetabling was also realized for microcomputers (Foulds \& Johnson, 2000).

If the model of the timetable planning is solved as a constraint-satisfaction problem, it can be solved by genetic algorithm (Deris et al., 1999). In this case, the solution procedure is based on a constraint-based reasoning technique implemented in an object-oriented approach (Deris et al., 2000).

Timetabling problem can even be more complicated in case of irregular weekly timetables. This problem was successfully solved by decomposed metaheuristic approach (De Causmaecker et al., 2009). University timetabling is the typical optimization problem. Therefore there was created Stochastic Optimisation Timetabling Tool to decrease the amount of required computation (Pongcharoen et al., 2008). Due to the optimization problem the university course timetabling deals with decomposition and reformulation (Burke et al., 2010).
The last results in the field of university timetabling problems shows that it is useful to use multi neighbourhood structures and memetic approach, or a combination of genetic algorithm and Tabu Search algorithm (Abdullah \& Turabieh, 2012).

The paper is organized as follows. Firstly, the new mathematical model of the room occupancy is formulated. At the end of this chapter, the list of used symbols is provided. This is followed by example of usage. The model was used to determine the room occupancy at the Faculty of Applied Informatics, Tomas Bata University in Zlin, Czech Republic, in the school year 2012/2013.

\section{MATHEMATICAL MODEL OF ROOM OCCUPANCY}

Since the author of this model creates the faculty timetable for several years, the model is based on the personal experience of the author in this field. The model is original one and it was created from scratch. It is based on the faculty data and therefore it has to be modified for the general usage. List of symbols is provided after the last equation. Total number of rooms is the main output of this new model. It is counted as the sum of total number of lecture halls and the total number of seminary rooms and the total number of laboratories and rooms with PCs according to

$$
R t=R l+R s+R p c
$$

Total number of hours is counted as the sum of total number of hours in lecture halls and the total number of hours in seminary rooms and the total number of hours in laboratories and rooms with PCs as

$$
H t=H l+H s+H p c
$$

Number of rooms is counted as the number of hours multiplied by room occupancy coefficient and rounded up to the closest integer number

$$
R i=R u(H i * C r o)
$$

Total number of hours in seminary rooms is counted as the number of seminary hours of concrete subject multiplied by the number of scheduled groups at given specialization and year of studies over all subjects taught at given specialization and year of studies and over all 
years of studies and over all specializations. It is counted as

$$
H s=\sum_{S n=1}^{n} \sum_{Y n=1}^{5} \sum_{S t n=1}^{m} S c s_{S n, Y n, S t n} * G s y_{S n, Y n, S t n}
$$

Total number of hours in laboratories and rooms with PCs is counted as the sum of the total number of hours in small rooms with PC and total number of hours in large rooms with PC and total number of hours in laboratories.

$$
H p c=H s p c+H l p c+H t l
$$

Total number of hours in laboratories is counted as the total number of hours in concrete laboratory over all laboratories

$$
H t l=\sum_{L a b=1}^{p} H t c l_{L a b}
$$

Total number of hours in concrete laboratory is number of laboratory hours of concrete subject multiplied by number of scheduled groups at given specialization and year of studies multiplied by two over all subjects taught at given specialization and year of studies and over all years of studies and over all specializations.

$$
H t c l_{L a b}=\sum_{S n=1}^{n} \sum_{Y n=1}^{5} \sum_{S t n=1}^{m} 2 * S c l_{S n, Y n, S t n} * G s y_{S n, Y n, S t n}
$$

Total number of hours in small rooms with $\mathrm{PC}$ is number of hours of concrete subject in small rooms with PC multiplied by number of scheduled groups at given specialization and year of studies multiplied by two over all subjects taught at given specialization and year of studies and over all years of studies and over all specializations. Number two in the term is due to the fact that every laboratory has half capacity taking into account the number of students in scheduled group.

$$
H s p c=\sum_{S n=1}^{n} \sum_{Y n=1}^{5} \sum_{S t n=1}^{m} 2 * S c s p c_{S n, Y n, S t n} * G s y_{S n, Y n, S t n}
$$

Total number of hours in large rooms with $\mathrm{PC}$ is number of hours of concrete subject in large rooms with PC multiplied by number of scheduled groups at given specialization and year of studies over all subjects taught at given specialization and year of studies and over all years of studies and over all specializations.

$$
H l p c=\sum_{S n=1}^{n} \sum_{Y n=1}^{5} \sum_{S t n=1}^{m} S c l p c_{S n, Y n, S t n} * G s y_{S n, Y n, S t n}
$$

Total number of hours in lecture halls is total number of hours in concrete lecture hall ove all lecture halls.

$$
H l=\sum_{L h=1}^{q} H t c l h_{L h}
$$

Total number of hours in concrete lecture hall is number of hours of concrete subject in lecture halls over all subjects taught at given specialization and year of studies and over all years of studies and over all specializations.

$$
H t c l h_{L h}=\sum_{S n=1}^{n} \sum_{Y n=1}^{5} \sum_{S t n=1}^{m} S c l h_{S n, Y n, S t n}
$$

Capacity of lecture hall has to fulfill the condition

$$
\text { Clh }>N s g * A n s
$$

which means that the capacity of lecture hall has to be larger than the result of number of scheduled groups multiplied by the average number of students in scheduled group. Substituting the equations in the equation counting the total number of rooms gives the final form of the created model counting the total number of rooms as

$$
\begin{aligned}
& \text { Rt } \\
& =R u\left(\operatorname{Cro} \sum_{L h=1}^{q} \sum_{S n=1}^{n} \sum_{Y n=1}^{5} \sum_{S t n=1}^{m} S c l h_{S n, Y n, S t n}\right) \\
& +R u\left(\operatorname{Cro} \sum_{S n=1}^{n} \sum_{Y n=1}^{5} \sum_{S t n=1}^{m} S c s_{S n, Y n, S t n}\right. \\
& \left.* G s y_{S n, Y n, S t n}\right) \\
& +R u\left(\left(\sum_{S n=1}^{n} \sum_{Y n=1}^{5} \sum_{S t n=1}^{m} 2 * S c S p c_{S n, Y n, S t n}\right.\right. \\
& * G s y_{S n, Y n, S t n} \\
& +\sum_{S n=1}^{5} \sum_{Y=1}^{m} \sum_{S t n=1}^{n} S c l p c_{S n, Y n, S t n} * G s y_{S n, Y n, S t n} \\
& +\sum_{L a b=1}^{n} \sum_{S n=1}^{m} \sum_{Y n=1}^{m} \sum_{S t n=1}^{m} 2 * S c l_{S n, Y n, S t n} \\
& * G s y_{S n, Y n, S t n} * C r o
\end{aligned}
$$

There were used following symbols in the equations:

Ans is average number of students in scheduled group

$C l h$ is capacity of lecture hall

Cro is room occupancy coefficient

$G s y_{S n, Y n, S t n}$ is number of scheduled groups at given specialization and year of studies

$H i$ is number of hours, where $i$ is $t, l, s$, and $p c$

$\mathrm{Hl}$ is total number of hours in lecture halls

$H l p c$ is total number of hours in large rooms with PC

$H p c$ is total number of hours in laboratories and rooms with PCs

$H s$ is total number of hours in seminary rooms 
Hspc is total number of hours in small rooms with PC $H t$ is total number of hours

$\mathrm{Htclh}_{L h}$ is total number of hours in concrete lecture hall $\mathrm{Htcl}_{\text {Lab }}$ is total number of hours in concrete laboratory $\mathrm{Htl}$ is total number of hours in laboratories

$L a b$ is laboratory, $L a b$ is $1,2, \ldots, p$

$L h$ is lecture hall, $L h$ is $1,2, \ldots, q$

$N s g$ is number of scheduled groups

$R i$ is number of rooms, where $i$ is $t, l, s$, and $p c$

$R l$ is total number of lecture halls

$R p c$ is total number of laboratories and rooms with PCs

$R s$ is total number of seminary rooms

$R t$ is total number of rooms

$R u$ is round up

$S c l h_{S n, Y n, S t n}$ is number of hours of concrete subject in lecture halls

$S c l p c_{S n, Y n, S t n}$ is number of hours of concrete subject in large rooms with PC

$S c l_{S n, Y n, S t n}$ is number of laboratory hours of concrete subject

$S c s p c_{S n, Y n, S t n}$ is number of hours of concrete subject in small rooms with PC

$S c s_{S n, Y n, S t n}$ is number of seminary hours of concrete subject

$S n$ is specialization, $S n$ is $1,2, \ldots, n$

Stn is subject taught at given specialization and year of studies, Stn is $1,2, \ldots, m$

$Y n$ is years of studies, $Y n$ is $1,2, \ldots, 5$

\section{EXAMPLE OF USAGE}

The model was implemented in MS Excel for this school year.

There are several input tables such as the one shown in figure 1 used to count the occupancy. The last 3 columns from this table are used in model. Fig. 2 and 3 shows the main sheet with the rooms' occupancy and their number. Sample input table of the model includes the following columns: the taught subject abbreviation is in the first column, the abbreviation of department guaranteeing the taught subject is in second column, the name of the taught subject in the Czech language is in third column. Columns 2 and 3 are just informative. They are not used by the model. Fourth column includes the number of hours in lecture halls per week of taught subject. There are number of hours in seminary rooms per week of taught subject in next column.

The last but one column includes the number of hours in laboratories and rooms with PCs per week of taught subject. If there is non-zero value in the last but one column than there are datas in the last column in the corresponding rows. The sample input table of the model in figure 1 includes data for one specialization, half of year and one year of studies. Combination of years of studies and specializations gives 22 input tables which were used by the model to count the room occupancy. Figures 2 and 3 show the main sheet but not only with results but also with some input data as well. Input data are written in yellow cells. In figure 2, there are tree blocks of yellow cells and one yellow cell in figure 3 .

\begin{tabular}{|c|c|c|c|c|c|c|}
\hline & & & $\mathrm{P}$ & $\mathrm{s}$ & C & \\
\hline A1ZMA & AUM & Základy matematiky & 2 & 2 & 0 & \\
\hline $\mathrm{A} 1 \mathrm{ZPT}$ & AURP & Základy počítačové technilky & 0 & 0 & 2 & $\mathrm{PC}$ \\
\hline A1SBP & $A U B I$ & Systemizace bezpečnostnîho prủmyslu & 3 & 0 & 1 & 54315 \\
\hline A1FBT & AUEM & Fyzika v bezpečnostnich technologiich & 2 & 0 & 2 & largePC \\
\hline A1PRR & $A U B I$ & Právní rád I & 3 & 1 & 0 & \\
\hline A1ING & TUVI & Inženýrská grafika & 1 & 0 & 2 & $\mathrm{PC}$ \\
\hline A1MAI & AUM & Matematika I & 2 & 4 & 0 & \\
\hline A1STP & AUBI & Speciální tĕlesná príprava 1 & 1 & 0 & 2 & TV \\
\hline
\end{tabular}

Fig. 1. Sample input table of the model - table 1

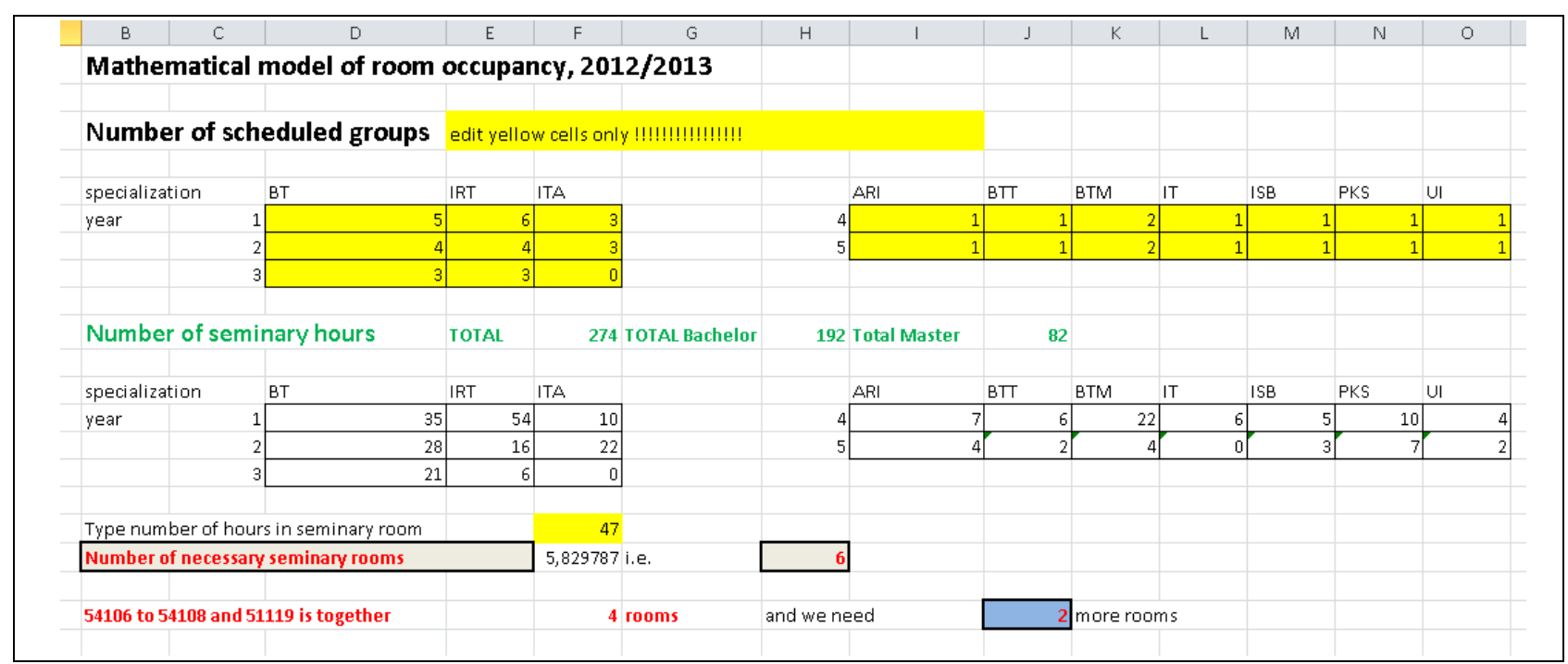

Fig. 2. Main sheet - occupancy of seminary rooms and their number 


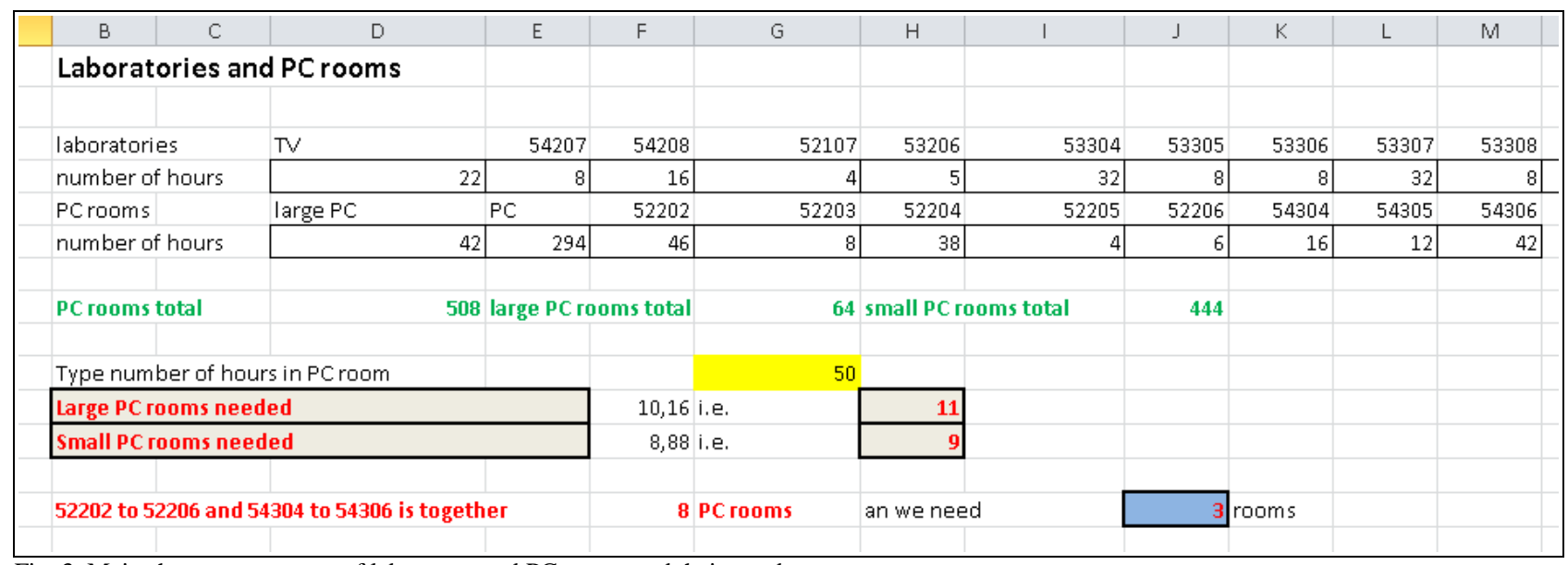

Fig. 3. Main sheet - occupancy of laboratory and PC rooms and their number

In first block, 3x3, which means 9 cells, user can write number of scheduled groups at given specialization and year of studies for Bachelor studies. Rows give the year of studies and column the given specialization.

Second block, $2 \times 7$, which means 14 cells, is similar to block one, and it is valid for Master studies. Rows give the year of studies from the beginning, it means from the beginning of Bachelor studies, and column the given specialization. Data from these two blocks of cells are crucial for room occupancy. User can see and type how many scheduled groups at given specialization and year of studies he/she wants but with respect not to exceed the capacity of chosen room, for example some laboratory.

The last editable block in figure 2 allows user to type how many hours per week can be taught in seminary rooms in average. The main result is the number of required seminary rooms. Since there is a given number of seminary rooms in the faculty buildingins but combination of input data can theoretically give arbitrary number of seminary rooms, there is one blue cell in figure 2. The blue cell in figure 2 says how many seminary rooms are over the given number of seminary rooms in the faculty buildingins.

There are two black and white tables in figure, which show partial results, the weekly occupancy of seminary rooms at given specialization and year of studies. The tables are organized as those two ones described as first and second block. Table in left is for Bachelor studies, table in right for Master studies. Rows give the year of studies and column the given specialization. The green line gives three numbers, total number of hours taught in all seminary rooms per week, total number of hours for Bachelor studies taught in all seminary rooms per week, and total number of hours for Master studies taught in all seminary rooms per week. Figure 3 deals with the room occupancy in laboratories and PC rooms. There is only one input cell, the yellow one. It allows user to type how many hours per week can be taught in PC rooms in average.

\section{CONCLUSION}

There was introduced and applied the new mathematical model counting room occupancy, or number of hours per week respectively, which is presented in this paper. Due to this model, there is no need to create "zero version of timetable" which was created only in purpose to reveal the room occupancy.

In future, this model will be offered to other faculties to use it, because they have similar problem, to determine the room occupancy before the timetable is created. Their experience will be collected and the model will then be modified according the needs of other users. After that, the model will be used in new software for time-table creation.

\section{REFERENCES}

[1] Abdulah, S. \& Turabieh, H. (2012). On the use of multi neighbourhood structures within a Tabu-based memetic approach to university timetabling problems. Information Sciences, 191, pp. 146-168

[2] Burke, E.K., Marecek, J., Parkes, A.J. \& Rudova, H. (2010). Decomposition, reformulation, and diving in university course timetabling. Computers \& Operations Research, 37, pp. 582-597

[3] Daskalaki, S. \& Birbas, T. (2005). Efficient solutions for a university timetabling problem through integer programming. European Journal of Operational Research, 160, pp. 106-120

[4] De Causmaecker, P., Demeester, P. \& Berghe, G.V. (2009). A decomposed metaheuristic approach for a real-world university timetabling problem. European Journal of Operational Research, 195, pp. 307-318

[5] Deris, S., Omatu, S. \& Ohta, H. (2000). Timetable planning using the contraint-based reasoning. Computers \& Operations Research, 27, pp. 819-840

[6] Deris, S., Omatu, S., Ohta, H. \& Saad, P. (1999). Incorporating constraint propagation in genetic algorithm for university timetable planning. Engineering Applications of Artificial Intelligence, 12 , pp. 241-253

[7] Dimopoulou, M. \& Miliotis, P. (2001). Implementation of a university course and examination timetabling system. European Journal of Operational Research, 130, pp. 202-213

[8] Dimopoulou, M. \& Miliotis, P. (2004). An automated university course timetabling system developed in a distributed environment: A case study. European Journal of Operational Research, 153, pp. 136-147

[9] Foulds, L.R. \& Johnson, D.G. (2000). SlotManager: a microcomputer-based decision support system for university timetabling. Decision Support Systems, 27, pp. 367-381

[10] Katalinic, B. (2010). Engineers for knowledge based society, Proceedings of the $21^{\text {st }}$ International DAAAM Symposium, Volume 21, No. 1, ISSN 1726-9679, ISBN 978-3-901509-73-5, Katalinic, B. (Ed.), DAAAM International Vienna, Austria, EU

[11] Pongcharoen, P., Promtet, W., Yenradee, P. \& Hicks, C. (2008). Stochastic Optimisation Timetabling Tool for university course scheduling. International Journal of Production Economics, 112, pp. $903-918$ 